\title{
LOS PROGRAMAS DE DESARROLLO RURAL EN LA PROVINCIA DE ZAMORA: ¿INICIATIVAS CAPACES DE DINAMIZAR EL ATRASO SOCIOECONÓMICO DE SUS ESPACIOS RURALES?
}

\author{
Antonio MAYA FRADES \\ Departamento de Geografia. Universidad de León
}

El descenso progresivo del peso del sector agrario y los cambios inducidos por las sucesivas reformas de la Politica Agrícola Común (PAC.) han introducido una serie compleja de problemas en los espacios rurales que han afectado a sus estructuras, al tejido socioeconómico y a sus hábitos productivos. Al mismo tiempo, no hemos de obviar que dicho sector ha sido durante mucho tiempo la principal fuente de ingresos y de empleo de la población agraria, por lo que ante su reestructuración parece oportuno potenciar la diversificación de la economia rural, basada en la implantación de nuevas actividades alternativas o complementarias de las tradicionales con el fin de mejorar sus niveles de renta.

A lo largo del tiempo, la Unión Europea (UE.) ha mantenido una continua preocupación por los espacios rurales, aunque con desiguales objetivos y resultados, y ha tratado de adaptar sus inquietudes a las transformaciones que se han ido introduciendo en los mismos. Quizá el documento base que mejor refleje esa situación es El futuro del mundo rural (1988), en el que se exponía el diagnóstico y los problemas que presentaba el mundo rural y, al mismo tiempo, ya se insinuaban las iniciativas y los instrumentos que se debian aplicar con el fin de corregir los desequilibrios y adecuarlos a las nuevas realidades socioeconómicas y territoriales.

El interés por el desarrollo rural ha continuado, quedando claramente recogidos los planteamientos para el próximo milenio en dos marcos muy concretos: la Declaración de Cork (1996) y la Agenda 2000 (1997). En la primera, se pone el acento en el medio rural y otorga un papel cada vez más relevante al mundo rural, al margen del ámbito agrícola, pero considerando a este último como el eje articulador de la vida rural. La Agenda 2000 toma como suyas esas reflexiones, convirtiendo al desarrollo rural en un pilar básico de la P.A.C., e insiste en aplicar a los espacios rurales un enfoque integrado, multidisciplinar y racional; se plantea una estrategia de desarrollo rural que garantice el futuro a largo plazo (empleo, calidad de vida y medio ambiente) y responda al mismo tiempo a las exigencias de adaptación estructural del sector agrario y al desarrollo socioeconómico de las áreas rurales. También se va a conceder atención, entre otros objetivos, a la mejora de la capacidad local para el desarrollo rural, el estímulo al asociacionismo y la coparticipación de los agentes locales, la potenciación del enfoque ascendente o de abajo

Poligonos, n 8, 1999, pp. 99-128. 
hacia arriba o el importante papel que juegan la inversión y la financiación privadas.

Así pues, los espacios rurales han recibido un tratamiento especial con el fin de que sus estructuras socioeconómicas no se desarticulen y sigan manteniendo en buen estado de conservación su rico y variado patrimonio heredado. Junto a las funciones tradicionales de productores de alimentos y de materias primas, se han aplicado políticas que tratan de difundir el desarrollo rural como otra alternativa económica complementaria de aquéllas. Con ello se pretende que en el mundo rural se lleve a cabo una adecuada gestión y ordenación del territorio en la que prime el enfoque integrado y trate de mejorar las condiciones de vida y trabajo de la población mediante la creación de empleo y riqueza, compatibles con la preservación del medio y el uso sostenible de los recursos naturales.

Con el fin de lograr mejor los objetivos del desarrollo rural, la U.E. ha articulado una serie de instrumentos simples y flexibles, entre los que destaca la Iniciativa Comunitaria LEADER II (Liaisons entre Actions de Développement de l'Economie Rurale); también se debe mencionar el programa PRODER (Programa de Diversificación Económica de las Zonas Rurales) impulsado por las Administraciones Central, Regional y Local.

La provincia de Zamora, como área eminentemente rural, con un notable atraso económico y zona objetivo 1 , ha recibido durante los últimos años diversos programas de desarrollo rural que actúan sobre las comarcas con dificultades socioeconómicas ${ }^{1}$. Dichos programas se refieren básicamente al LEADER $\Pi^{2}$ y al Programa PRODER ${ }^{3}$. En torno al $70 \%$ de la superficie provincial está afectada por estas iniciativas, siendo las comarcas fronterizas las más intervenidas. En ellas vive la tercera parte de la población provincial y su densidad media es sólo de 10,5 habitantes $/ \mathrm{Km}^{2}$, lo que pone de manifiesto su crítica dinámica demográfica y el acentuado éxodo rural acaecido en décadas precedentes (CUADRO 1). Son espacios bastante despoblados y además están afectados por otro grave problema estructural: su acusado envejecimiento, derivado del débil o negativo crecimiento natural y la ausencia de jóvenes; todo ello, junto a otras causas de diversa índole, como, entre otras, el retroceso de las actividades económicas tradicionales, el anquilosamiento del aparato productivo, las defícientes infraestructuras, la degradación del patrimonio, la pérdida de identidad cultural o la carencia de servicios básicos, no está incidiendo favorablemente en la aceptación de las iniciativas o en la aplicación de las perspectivas de desarrollo rural que se pueden dar en estas zonas desfavorecidas y con continuos procesos de desarticulación.

\footnotetext{
${ }^{1}$ La información utilizada para elaborar este articulo ha sido amablemente facilitada por la Dirección General de Industrias Agrarias y Desarrollo Rural de la Junta de Castilla y León. Quiero dejar constancia de la atención dispensada y las sugerencias aportadas por D. Victorino Rubio, quien nos atendió muy diligentemente; agradecimiento que también deseo extenderlo a los gerentes de los LBADER II y de los PRODER de la provincia de Zamora.

${ }^{2}$ Aunque el Programa Marco del LEADER II se firmó el 15 de junio de 1994, el convenio no empezó a funcionar hasta el 27 de octubre de 1995.

${ }^{3}$ El convenio del Programa PRODER se rubricó el 7 de julio de 1997.
} 
Cuadro 1: Los programas LEADER II y PRODER en la provincia de Zamora.

\begin{tabular}{llrrr}
\hline & Denominación & $\begin{array}{r}\text { Municipios } \\
(\text { Número) }\end{array}$ & $\begin{array}{c}\text { Extensión } \\
\left(\mathbf{K m}^{2}\right)\end{array}$ & $\begin{array}{c}\text { Población } \\
(\mathbf{H a b i t a n t e s )}\end{array}$ \\
\hline LEADER & ADRI-Palomares & 69 & 1.954 & 26.508 \\
& ADATA & 31 & 2.018 & 17.000 \\
\hline Total LEADER & & 100 & 3.972 & 43.508 \\
\hline PRODER & Sanabria & 28 & 1.898 & 12.000 \\
& Sayago & 26 & 1.564 & 13.649 \\
\hline Total PRODER & & 54 & 3.462 & 25.649 \\
\hline Total Programas & & 154 & 7.434 & 69.157 \\
\hline Provincia Zamora & & 248 & 10.561 & 207.475 \\
\hline
\end{tabular}

\section{LA INCIDENCIA DE LA INICIATIVA LEADER II: SU AC- TUACIÓN EN COMARCAS DE DESIGUALES CARACTERÍS- TICAS FISICAS Y ORIENTACIÓN ECONÓMICA.}

En la provincia de Zamora no hubo intervención del LEADER I, por lo que las actuaciones derivadas de esa iniciativa comunitaria corresponden al LEADER II. Éste interviene en dos comarcas agrarias: Aliste y la Tierra de Campos-Pan, que presentan desiguales características geográficas, en particular en cuanto a sus aspectos fisicos, como la configuración geomorfológica y edáfica. La primera se incluye en el dominio de las penillanuras occidentales de la provincia, siendo los materiales paleozoicos el sustrato geológico, que influye en que los suelos sean pobres y en que su vocación preferente se base en la ganaderia extensiva. La Tierra de Campos, por el contrario, se integra dentro de la cuenca sedimentaria y de las campiñas campesinas de clara aptitud agricola. Esas diferentes orientaciones económicas han marcado su desarrollo agrario, convirtiéndose, en cierta medida, en algunas de las claves para las iniciativas de su actual desarrollo rural.

Las dos iniciativas LEADER II comprenden las dos terceras partes de los municipios y se extienden casi por la mitad de la superficie afectada por los programas de desarrollo rural. En ellos viven, según el censo de 1996, unas 43.500 personas, que representan casi los dos tercios de los habitantes acogidos a los mismos, teniendo también una baja densidad media: 11 habitantes/Km2, derivado de las causas anteriormente mencionadas.

\subsection{EI LEADER II de la comarca de Aliste $^{4}$ : el turismo rural como medida más implantada y más desarrollada.}

Aliste, en la que se incluyen, además de Aliste, las comarcas históricas de Tábara y Alba, es una comarca periférica que se localiza al Oeste de la provincia de

\footnotetext{
${ }^{4}$ Su denominación completa es. ADATA (Asociación para el Desarrollo de Aliste, Tábara y Alba); el titular del mismo es dicha asociación. Su sede se localiza en Alcañices.
} 
Zamora y raya con Portugal; su posición excéntrica y con escaso desarrollo económico la convierten en una de las bolsas de pobreza del occidente peninsular. Estas características, junto a las anteriormente mencionadas, están incidiendo en las iniciativas que se van a poder abordar con el fin de dinamizar el desarrollo rural de la misma. Son condicionantes que van a tener un elevado peso y van a marcar su capacidad innovadora.

Comprende 31 municipios, que ocupan una extensión de $2.018 \mathrm{Km}^{2}$ y viven 17.000 personas, resultando una densidad media de 8,4 habitantes $/ \mathrm{Km}^{2}$. La actividad agraria es la base económica de la comarca, aunque, debido a su estructura demográfica envejecida (los mayores de 65 años suponen casi la tercera parte, mientras que los de menos de 15 años sólo representan el $8,8 \%$ de la población de 1996) y, por ende, al notable peso de los jubilados, se complementa con las pensiones agrarias que se destinan casi íntegramente al ahorro; es una comarca, como las otras dos fronterizas: Sanabria y Sayago, con una gran capacidad de ahorro debido a que desde siempre, como consecuencia de las limitaciones de las producciones agrarias, las personas han llevado una vida austera y llena de carencias en todos los sentidos.

Cuadro 2: Inversión prevista y comprometida en el LEADER II de Aliste (miles de ptas.).

\begin{tabular}{|c|c|c|c|c|c|}
\hline \multirow{2}{*}{ Medidas } & \multicolumn{2}{|c|}{ Inversión prevista } & \multicolumn{2}{|c|}{ Inv. comprometida (1) } & \multirow[b]{2}{*}{$\%(2)$} \\
\hline & Cantidad & $\%$ & Cantidad & $\%$ & \\
\hline Apoyo técnico & $111.360,0$ & 9,6 & 63.689 & 13,0 & 57,2 \\
\hline Formación profesional & $28.960,0$ & 2,5 & 4.780 & 1,0 & 16,5 \\
\hline Turismo rural & $332.480,0$ & 28,8 & 165.344 & 33,0 & 49,7 \\
\hline PYMES & $173.280,0$ & 15,0 & 99.995 & 21,0 & 57,7 \\
\hline Comercialización agraria & $216.640,0$ & 18,7 & 70,830 & 15,0 & 32,7 \\
\hline Medio ambiente & $292.800,0$ & 25,4 & 80.857 & 17,0 & 27,6 \\
\hline TOTAL & $1.155,5$ & 100,0 & 485.495 & 100,0 & 42,0 \\
\hline
\end{tabular}

FUENTE: Dirección General de Estructuras Agrarias y Desarrollo Rural. Consejeria de Agricultura y Ganadería. Junta de Castilla y León. (Elaboración propia).

La inversión prevista en esta iniciativa comunitaria, para el periodo 1994-99, asciende a $1.156,5$ millones de pesetas, de los cuales el $60 \%$ de la financiación corresponde a gastos públicos de las distintas administraciones ${ }^{5}$ (U.E., Central, Autonómica y Local) y el $40 \%$ restante a los gastos de las diversas iniciativas privadas. Las medidas a las que se le ha asignado mayor cuantia económica son aquellas que ofrecen mejores y mayores posibilidades de ser desarrolladas y de constituir un tejido productivo capaz de generar rentas agrarias complementarias

\footnotetext{
${ }^{5}$ La U.E. contribuye a dicha financiación con el $45 \%$, mientras que las distintas administraciones españolas aportan el $15 \%$ restante.
} 
a la población de la comarca; concretamente, son las de turismo rural, conservación y mejora del medio ambiente, valoración y comercialización de la producción agraria y la creación de pequeñas empresas (CUADRO2).

Las propuestas del cuadro financiero previsto no han finalizado aún, por lo que hasta el mes de junio de 1998 la inversión comprometida era de 485,5 millones de pesetas, que representan el $42 \%$ del total del programa. Aunque sólo queda un año para que finalice, es una proporción bastante elevada, si tenemos en cuenta, tal como ya se ha expuesto, que tardó bastante tiempo en iniciar su andadura.

Las medidas de la inversión comprometida no han mantenido un desarrollo similar, sino que las más avanzadas, en cuanto a las iniciativas ya aprobadas, son en particular las relacionadas con el turismo rural y con la creación de pequeñas empresas, la artesania y los servicios (FIGURA 1). Similar situación se aprecia si comparamos la inversión comprometida con la prevista (CUADRO 2), aunque, en este caso, hay que añadir la medida de apoyo técnico; de ésta depende económicamente el funcionamiento del Grupo de Acción Local (GAL.). La que menos impulso ha recibido, aunque también es la que menos representa en todos los sentidos, ha sido la de formación profesional y ayudas a la contratación; se tendria que haber desarrollado más con el fin de crear un ambiente favorable capaz de ampliar el tejido social susceptible de acogerse a estas iniciativas.

El origen de la aportación de capital comprometido también varía según las distintas medidas (FIGURA 1). En la de turismo rural, que es la que más desarrollo ha alcanzado, el capital de iniciativa privada se hace cargo del $61 \%$ de las inversiones, correspondiendo el resto a Ias distintas administraciones: $30 \%$ la U.E. (el Fondo Europeo de Desarrollo Regional- FEDER- el 21\%, y el Fondo Europeo de Orientación y Garantía Agrarias -FEOGA-, el $9 \%$ ) y $8 \%$ las nacionales (Central, Autonómica y Local). A continuación se sitúa la medida destinada al fomento de las PYMEs, de la artesanía y de los servicios, en la que la actuación del capital privado también ocupa un lugar destacado con el $65 \%$ de la inversión, aportando la U.E. el $29 \%$ (FEDER y FEOGA a partes iguales) y el $6 \%$ las administraciones españolas; el desarrollo de esta medida se convierte en un hecho necesario para la comarca, pues de este modo se logra dotarla de un tejido productivo que sea capaz de dinamizar otras actividades económicas complementarias y, por ende, ampliar sus perspectivas de futuro.

En las otras medidas, con menos arraigo en la comarca que las anteriores, el reparto aparece, manteniendo el orden de importancia de las mismas, del siguiente modo. En la destinada a la conservación y mejora del medio ambiente y del entorno, las aportaciones de los diversos capitales son muy similares: el privado participa con el $38 \%$, la U.E. con el $39 \%$ (la mayoría de los fondos corresponden al FEDER) y las administraciones españolas con el $23 \%$. Dicha medida refleja, sin duda alguna, la constante preocupación por el mantenimiento y la protección del medio ambiente de las continuas agresiones sociales; de ahi que se convierta en una iniciativa que trate de introducir criterios más respetuosos y compatibles con el uso sostenible de los recursos. La valoración y comercialización de la producción agraria también ocupa un lugar destacado debido a que se dedica a fomentar y a obtener el máximo valor añadido de los productos locales, sin embargo, hasta ahora el capital comprometido representa muy poco; en este caso, la contribución 


\section{Figura 1}

Iniciativa comunitaria Leader II de las comarcas de Aliste, Tábara y Alba (1995-junio de 1998)

\section{Inversión comprometida según medidas y la aportación de capital (en pesetas)}

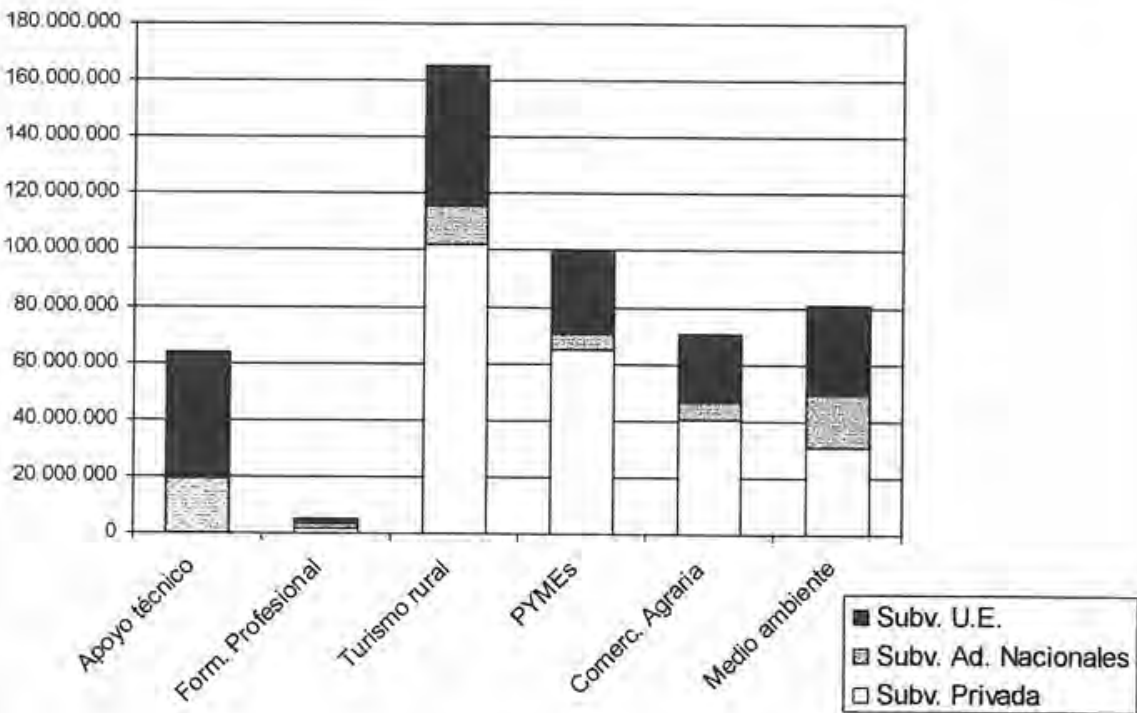

\section{Inversión comprometida según medidas}

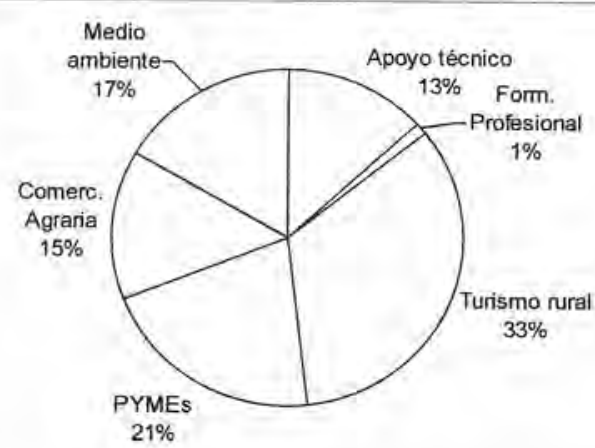


Figura 2: LEADER II de la comarca de Aliste.

Número de iniciativas según medidas
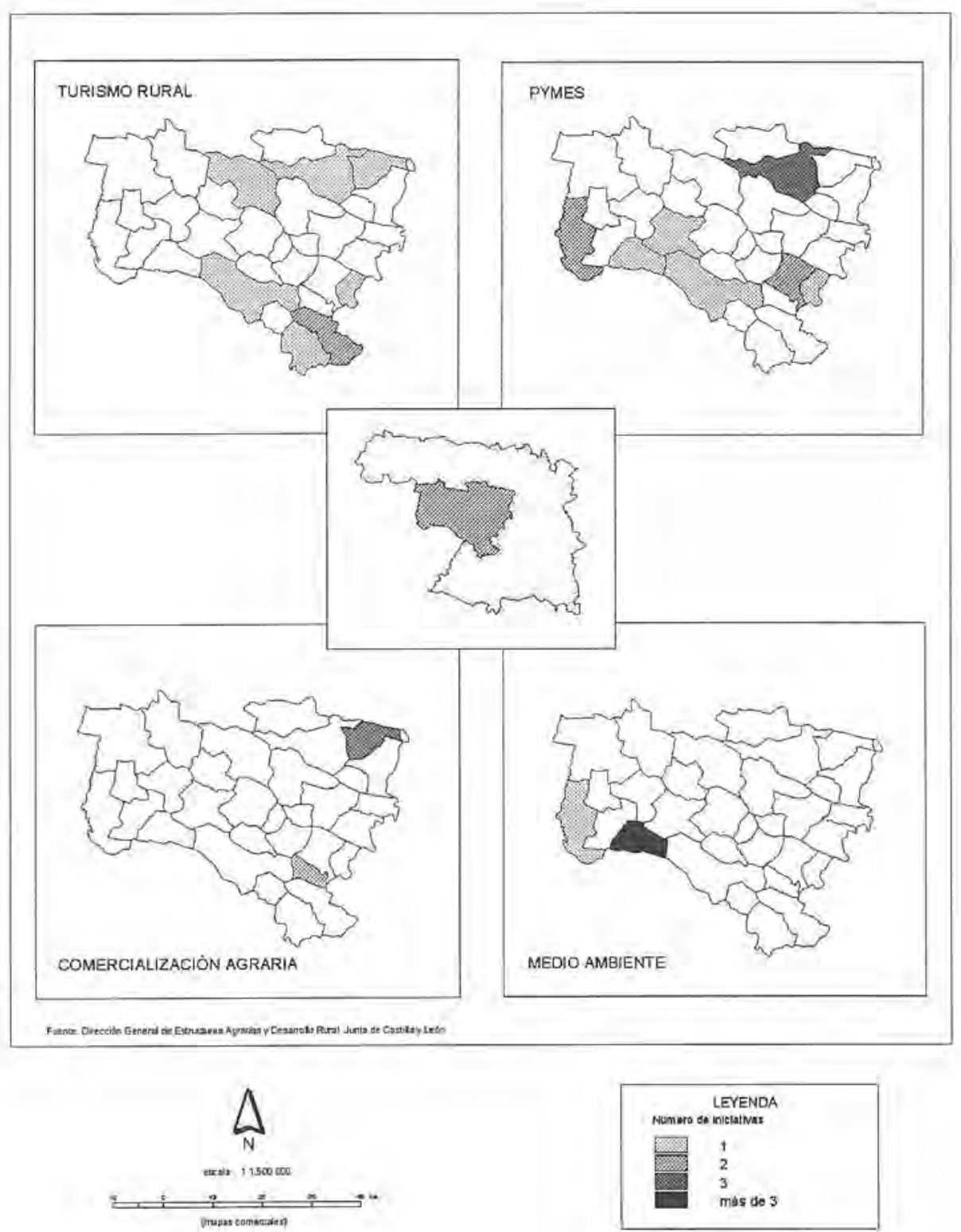
del capital privado es bastante elevada, ascendiendo al $57 \%$, mientras que la U.E. aporta el 35\% (sólo participa el FEOGA) y las nacionales el $8 \%$ restante.

Finalmente, restan dos acciones en las que el grueso de la aportación de capital corre a cargo de las distintas administraciones públicas; son medidas de apoyo y de fomento de las iniciativas que se basan en la innovación y en la expansión del desarrollo rural como formas capaces de dinamizar las áreas rurales y de crear estímulos e inquietudes en la población rural. En efecto, la de apoyo técnico al desarrollo rural, que cubre los gastos y las actividades desarrolladas por el G.A.L., y la de formación profesional y ayudas a la contratación, que se dedica a preparar un ambiente formativo adecuado para que sean aceptadas las diversas medidas, se ajustan perfectamente a esos objetivos.

$\mathrm{El}$ ámbito de aplicación de las diversas medidas es, obviamente, toda la comarca de Aliste (se incluyen, por supuesto, Tábara y Alba), sin embargo, la incidencia de las mismas desde el punto de vista territorial varia considerablemente. Nos centraremos preferentemente en las medidas que influyen en la transformación y en la mejora de la estructura socioeconómica de la comarca. En este sentido, tal como aparece en la FIGURA 2, en la medida de turismo rural se han llevado a cabo ocho actuaciones, que se refieren a la adecuación de casas o centros de turismo rural y de servicios de restauración (bares, bodegas o asadores) para cubrir la demanda que visita sus variados parajes naturales. La mayoría de los promotores son personas individuales y en algun caso empresas, variando bastante el capital invertido, desde los 9,5 hasta 51,5 millones de pesetas, lo mismo que la subvención pública, desde el $31 \%$ al $47 \%$ del total invertido. Dichas actuaciones se localizan de modo mayoritario al Este de la comarca en donde existen claros atractivos naturales, bien en las proximidades de los ríos (Esla y Aliste), bien en las cercanias de la Sierra de la Culebra.

La medida de creación de pequeñas empresas y fomento de la artesanía y servicios, como base para ampliar el tejido productivo, presenta una mayor distribución por la comarca (FIGURA 2). La mayor parte de las iniciativas es abordada por propietarios individuales, aunque también, a veces, la responsabilidad recae en pequeños empresarios. El número total de las acciones aprobadas asciende a once, oscilando el capital invertido desde las 400.000 hasta casi catorce millones de ptas.; la proporción de las subvenciones públicas fluctúa desde el $28 \%$ hasta el $45 \%$ del total capitalizado, correspondiendo el resto a la aportación privada. $\mathrm{Di}$ chas actuaciones se han centrado preferentemente en la creación de pequeñas empresas, entre las que se pueden mencionar, por un lado, las destinadas a prestar servicios a la comunidad rural, como la ampliación de carpinterias metálicas o la modernización de una empresa de medios audiovisuales, y, por otro, las que se dedican a la transformación de los productos locales, como la creación de una fábrica artesanal de elaboración de quesos de cabra, la compra de maquinaria para la conservación de setas e incluso la adquisición de maquinaria para la repoblación forestal con el fin de ampliar el espacio repoblado en la comarca.

La iniciativa referida a la valoración y comercialización de la producción agraria (FIGURA 2) contiene cinco actuaciones, localizadas preferentemente en dos municipios: Videmala y Faramontanos de Tábara. Los promotores de dichas acciones son básicamente pequeños empresarios y una cooperativa; se dedican, bien a la 
obtención de mayor valor añadido de los productos locales: una sala de despiece de producción cárnica, bien a productos que no tienen nada que ver con la comarca, como una granja de avestruces o una explotación cinegética de faisanes, y a la transformación de un producto exógeno como el lino textil, desarrollado al amparo de las cuantiosas ayudas de la PAC. La cantidad invertida va de los cuatro millones y medio hasta los cuarenta millones de ptas., oscilando las subvenciones públicas desde el 38 hasta el $48 \%$ de la inversión, aportando el capital privado el resto.

Por último, conviene mencionar la medida centrada en la conservación y mejora del medio ambiente y del entorno. Las acciones son nueve (FIGURA 2), ubicadas todas en el municipio de Alcañices, excepto una en el de Trabazos, y se dedican a actividades varias, destacando en particular las referidas a la restauración de fachadas de casas rurales con relevancia arquitectónica e histórica, a la edición de publicaciones donde se recogen rutas paisajísticas o itinerarios de claro contenido natural e histórico o a la conmemoración del séptimo centenario del Tratado de Alcañices (firma de la paz y del establecimiento de la frontera Norte entre los reinos de España y Portugal). En este caso, con el fin de difundir y dar a conocer los atractivos naturales y culturales de la comarca o debido a la rehabilitación del caserio o a los actos conmemorativos, las subvenciones públicas representan proporcionalmente bastante más que en los casos anteriores, desde el 20 hasta el $75 \%$, dependiendo de las actividades desarrolladas. Son medidas complementarias de las anteriores que tratan de crear unas condiciones favorables para que se mantenga en buen estado de conservación, en sentido amplio, el patrimonio heredado, es decir, fomentar aquellas actividades que sirvan de base para el desarrollo de la comarca y en particular para una de las medidas sobre la que existen más perspectivas: el turismo rural, que, como ya hemos puesto de manifiesto, es la que más desarrollo ha alcanzado hasta ahora.

Todas estas actuaciones abordadas por el programa de innovación rural han servido para generar inquietudes en la propia comarca y para que la población joven se implique en las mismas. Al mismo tiempo, han permitido que se consoliden o se creen unos 29 puestos de trabajo, que no son muchos, pero, sin duda alguna, incidirán en la ampliación del tejido productivo y en la aparición de alternativas económicas que hasta hace unos años eran impensables. $\mathrm{Al}$ margen de sus resultados, dicho programa es bastante positivo, pues ha influido en la reconsideración y en la puesta en valor de determinados recursos que anteriormente se despreciaban o no se concebian como capaces de aportar ingresos complementarios a la tradicional actividad agraria.

\subsection{EI Leader II de la comarca de Tierra de Campos ${ }^{6}$ : la valoración y la comercialización de la producción agraria y el turismo rural como me- didas más representativas.}

La Tierra de Campos, que está integrada por comarcas con cierta entidad geo-

\footnotetext{
${ }^{6}$ Su denominación completa es Asociación de Desarrollo Rural Integral (ADRI Palomares); el GAL es dicha asociación, que se encarga de su gestión. Su sede se ubica en Villafáfila.
} 
gráfica-histórica, como la propia Tierra de Campos, La Tierra del Pan o la comarca del Norte de Toro, se localiza en el cuadrante Nororiental de Zamora. Su posición periférica, respecto a la región de Castilla y León, influye en que sea un área de escaso desarrollo socioeconómico, aunque con mejores posibilidades económicas que la de Aliste. A pesar de ello, es una comarca que también requiere de iniciativas de desarrollo rural integrado con el fin de superar su atraso y postración económicas, que se han ido acentuando durante las últimas décadas debido tanto a factores endógenos como exógenos.

Está formada por 69 municipios que se extienden por $1.954 \mathrm{Km}^{2}$ y donde viven 26.508 personas, de lo que resulta una densidad media de $13,5 \mathrm{hab} . / \mathrm{Km}^{2}$.; es una densidad bastante pequeña que se halla alejada de la media provincial, que ya de por sí es baja (la provincia: unos $20 \mathrm{hab} . / \mathrm{Km}^{2}$ ), lo que denota, por un lado, el progresivo éxodo rural acaecido, acarreando un grave proceso de despoblamiento y abandono de los núcleos rurales, $y$, por otro, como consecuencia de ello se ha afianzado un fuerte envejecimiento de la población rural, quedando claramente constatado en que sólo el 10,1\% de los titulares tiene menos de 34 años, mientras que los de 55 y más años suponen más de la mitad del censo total. Todo ello está incidiendo de modo negativo en la comarca y sobre todo si tenemos en cuenta que nos encontramos ante un área en la que el peso del sector agrario en la economía es muy elevado; se trata de una comarca típicamente agrícola, localizada en plena cuenca sedimentaria y con favorables condiciones edáficas, aunque con ciertas limitaciones climáticas, por lo que las iniciativas de desarrollo deben tener en cuenta esos factores más positivos como elementos capaces de dinamizar y de buscar alternativas económicas para la comarca con el fin de convertirla en un espacio articulado, dinámico y vivo.

La inversión prevista, para el periodo 1994-99, asciende a 1.686 millones de ptas., de los que el $60 \%$ son aportados por las diversas administraciones ${ }^{7}$ (U.E., Central, Autonómica y Local) y el porcentaje restante por el capital privado. Las distintas medidas no reciben un trato similar, sino que las destinadas a configurar un tejido económico y productivo, que sirva para dinamizar la comarca, son las que reciben mayor cantidad de dinero (CUADRO 3), destacando en particular el turismo rural y la conservación y mejora del medio ambiente y del entorno, aunque tampoco se debe olvidar la valoración y comercialización de la producción agraria y las PYMES.

Ese cuadro financiero previsto aún no se ha ultímado. En junio de 1998, el capital comprometido en las diferentes medidas equivale a 984 millones, que supone el $58 \%$ del capital presupuestado para todo el periodo de vigencia del programa (CUADRO 3). Dicho grado de compromiso es bastante elevado -el mayor de todos los programas de desarrollo rural en la provincia de Zamora-, lo que nos pone de manifiesto que, a pesar de los problemas iniciales, dicho programa está siendo bien aceptado por los terracampinos.

\footnotetext{
${ }^{7}$ Lo mismo que en el LEADER de Aliste, la U.E. contribuye con el $45 \%$ del capital público, correspondiendo el $15 \%$ restante a las distintas administraciones españolas.
} 


\section{Figura 3}

Iniciativa comunitaria Leader II de la comarca de Tierra de Campos (1995-junio de 1998)

Inversión comprometida según medidas y la aportación de capital (en pesetas)

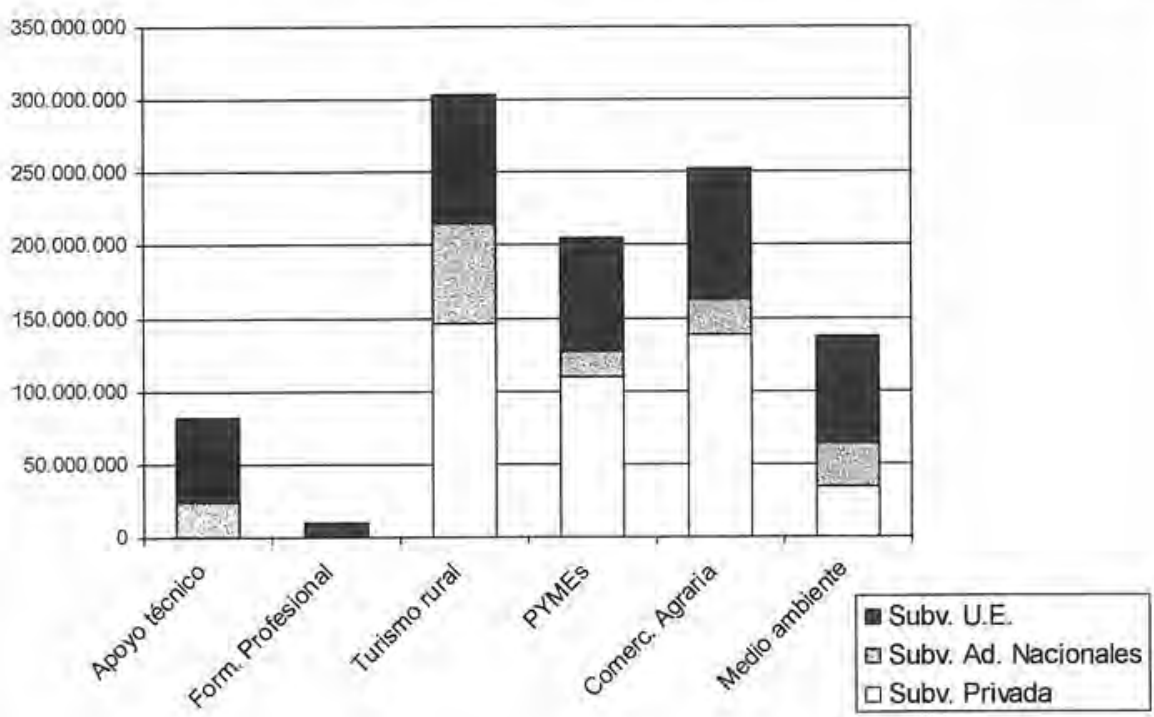

\section{Inversión comprometida según medidas}

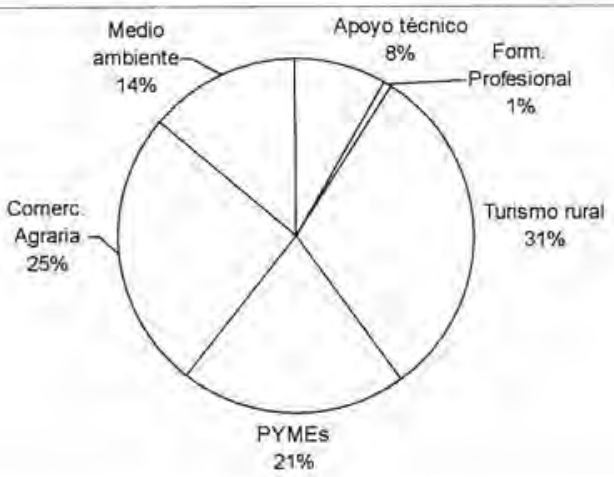


Figura 4: LEADER II de la comarca de Tierra de Campos. Número de iniciativas según medidas
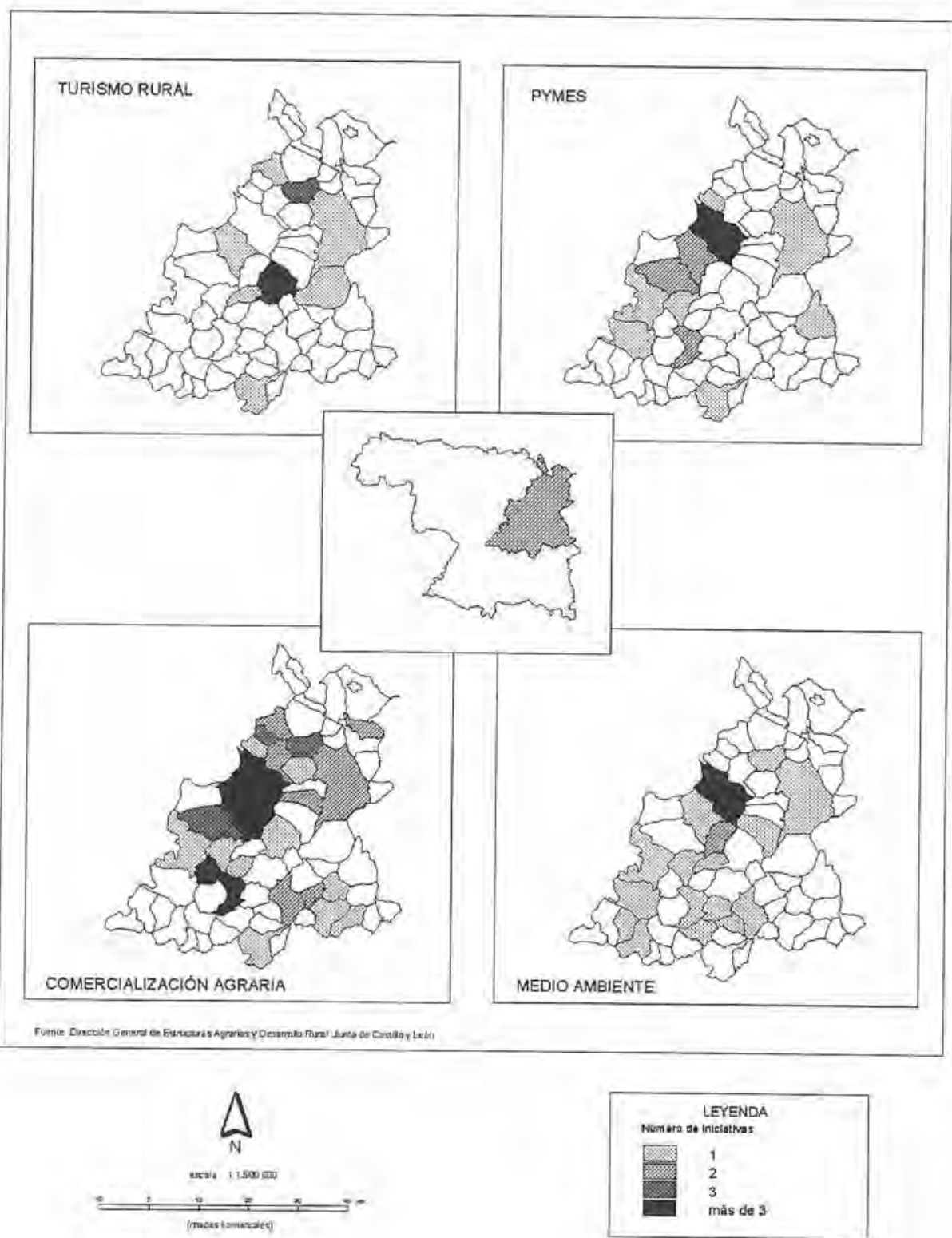
Cuadro 3: Inversión prevista y comprometida en el LEADER II de la Tierra de Campos (miles de ptas.).

\begin{tabular}{|c|c|c|c|c|c|}
\hline \multirow{2}{*}{ Medidas } & \multicolumn{2}{|c|}{ Inversión prevista } & \multicolumn{2}{|c|}{ Inv. comprometida (1) } & \multirow{2}{*}{$\%(2)$} \\
\hline & Cantidad & $\%$ & Cantidad & $\%$ & \\
\hline Apoyo técnic & 162.720 & 9,6 & 82.064 & 8,0 & 50,4 \\
\hline Formación profesional & 42.400 & 2,5 & 9.744 & 1,0 & 23,0 \\
\hline Turismo rural & 484.960 & 28,8 & 303.818 & 32,0 & 62,6 \\
\hline PYMES & 253.120 & 15,0 & 201.399 & 20,0 & 79,6 \\
\hline Comercializaci & 316.160 & 18,7 & 249.134 & 25,0 & 78,8 \\
\hline Medio ambiente & 427.360 & 25,4 & 137.875 & 14,0 & 32,3 \\
\hline TOTAL & $1,686,720$ & 100,0 & 984.034 & 100,0 & 58,3 \\
\hline
\end{tabular}

Notas: (1): Inversión comprometida hasta el mes de junio de 1998.

(2): \% de la inversión comprometida respecto a la prevista.

FUENTE: Dirección General de Estructuras Agrarias y Desarrollo Rural. Consejeria de Agricultura y Ganadería. Junta de Castilla y León. (Elaboración propia).

No todas las iniciativas han alcanzado el mismo grado de desarrollo comprometido, sino más bien sobresalen tres dentro del conjunto. Se trata, siguiendo un orden decreciente, del turismo rural, la valoración y comercialización de la producción agraria y las pequeñas empresas, la artesania y servicios (CUADRO 3 y FIGURA 3). Son las que, de momento, han mantenido una mejor aceptación, aunque no debemos olvidarnos de las tres restantes, pues cada una de ellas cumple una diferente función dentro de los planteamientos y de los objetivos generales del programa.

Similar situación se desprende de la comparación entre la inversión comprometida respecto de la prevista. En efecto, las medidas que han alcanzado mayor grado de compromiso son, de modo decreciente, las pequeñas empresas, la artesania y servicios, la valoración y comercialización de la producción agraria, el turismo rural y, además, ahora se añade la de apoyo técnico al desarrollo rural (CUADRO 3). De esta última depende económicamente para su funcionamiento el equipo técnico del G.A.L..

La procedencia del capital aportado en las diversas medidas también presenta claras diferencias internas (FIGURA 3). En la de turismo rural, que es la más desarrollada, el capital privado aporta el $48 \%$ de la inversión comprometida total, correspondiendo el resto a las distintas administraciones (la U.E. $E^{8}$, el $29 \%$, y las nacionales, el 23\%). En la de valoración y comercialización de la producción agraria la iniciativa privada se encarga del $55 \%$, responsabilizándose del resto las administraciones (la U.E $E^{9}: 35 \%$ y las nacionales: $10 \%$ ). En el fomento de las PYMES, de la artesania y de los servicios el porcentaje del capital privado también es ele-

\footnotetext{
${ }^{8}$ El FEDER contribuye con el $22 \%$ y el FEOGA con el $7 \%$.

${ }^{9}$ La totalidad de la subvención corresponde al FEOGA, pues dichas actividades se incluyen plenamente dentro de los objetivos desarrollados y financiados por dicho Fondo.
} 
vado $^{10}$, el $53 \%$, mientras que se reduce considerablemente en la conservación y mejora del medio ambiente ${ }^{11}, 25 \%$, y apenas es representativo en la medida de formación profesional y ayuda a la contratación ${ }^{12}$ o ninguno en el apoyo técnico al desarrollo rural.

La distribución territorial de las medidas difiere bastante, estando repartidas, las que tienen un claro componente espacial e incidencia sobre la configuración de la estructura y del tejido económicos de la comarca, del siguiente modo. La del turismo rural contiene diecisiete actuaciones (FIGURA 4), que se dedican a la adecuación de casas o centros para el turismo rural, a la construcción de un hotel o a la creación de servicios o actividades complementarias con el fin de ofertar atractivos suficientes que sirvan para atraer clientes a la comarca, como un picadero de caballos o un campo de golf. La mayoría de los promotores son propietarios privados, aunque también hay iniciativas desarrolladas por alguna empresa y, en particular, por los propios Ayuntamientos con el fin de dotar de infraestructuras ajustadas a la demanda y a la práctica del turismo rural. El capital total invertido se sitúa entre el millón y medio y los 90 millones de ptas., oscilando las subvenciones públicas desde el 22 hasta el $50 \%$ de la inversión y correspondiendo el resto a la aportación privada. La mayoria de las actuaciones se localizan en los núcleos de población de cierta importancia demográfica (Villalpando, Villafáfila, Coreses - Villarrín de Campos, por citar algunos de ellos) y que disponen de algunos servicios y atractivos suficientes de acuerdo a las preferencias de las personas que demandan el turismo rural.

La medida referida a la creación de pequeñas empresas y al fomento de la artesania y servicios contiene diecisiete actuaciones (FIGURA 4), que afectan básicamente a la creación de pequeñas empresas dedicadas a variadas actividades, bien aprovechando los productos locales, bien para prestar servicios a las propias comunidades rurales o a otros núcleos situados fuera de la comarca. Dicha diversidad comprende desde empresas centradas en la transformación del mármol (Torres del Carrizal), hasta las orientadas a la comercialización de productos de la tierra (Villafáfila), a la cría y explotación de conejos silvestres (Montamarta), a la modernización de una fábrica de muebles y remodelación de dos carpinterías-ebanisterias, la reforma de dos tiendas rurales o a la creación de una empresa agroalimentaria, por citar algunas de las más representativas. La mayor parte de los promotores son empresarios, aunque también aparecen propietarios privados y algunas sociedades colectivas, como las cooperativas. $\mathrm{El}$ capital invertido es inferior al destinado al turismo rural, ya que oscila desde el medio millón hasta los 31,5 millones de ptas.; la financiación pública aporta desde el 13 hasta el $55 \%$ de lo presupuestado, correspondiendo el resto al capital privado. Al igual que antes, las actuaciones se

\footnotetext{
${ }^{10}$ El capital público asciende al 47\%: la U.E., el 38\% (FEDER: $34 \%$ y Feoga: 4\%) y las administraciones nacionales, el $9 \%$.

${ }^{11}$ La inversión pública se sitúa en el $75 \%$ : la U.E. el $53 \%$ (FEDER: $36 \%$ y FEOGA: 17\%) y las administraciones nacionales, el $22 \%$.

${ }^{12} \mathrm{La}$ aportación de capital público equivale al 93\%: la UE. el 73\% (integramente cubierto por el FSE.) y las administraciones nacionales, el $20 \%$.
} 
sitúan preferentemente en los núcleos de cierta importancia, en un sentido amplio, aunque también participan otras entidades en la incorporación de las mismas con el fin de mejorar su estructura económica.

La iniciativa de la valoración y la comercialización de la producción agraria está más extendida por toda la comarca y se halla presente en un mayor número de municipios. Es la que contiene, además, un número más elevado de actuaciones, en concreto 64 (FIGURA 4), que superan con creces la incidencia de las dos medidas anteriores. El grueso de las actuaciones se integra en la diversificación de la producción agraria, que en realidad se refiere al arreglo y restauración de los palomares, pero no en el sentido de recuperar ese rico y peculiar patrimonio rural terracampino, que también se trata de fomentar, sino más bien orientado a la cría de palomas para la producción de carne ${ }^{13}$; con esta actividad, que es un buen ejemplo de la pluridiversidad, se pretende ampliar y complementar las fuentes de ingresos de las explotaciones agrarias; además, no hemos de olvidar que dichas aves se alimentan en las vastas campiñas cerealistas ajenas, con lo cual apenas acarrean gastos, siendo los ingresos básicamente integros. Junto a ello se han desarrollado otras actuaciones que se centran en la manipulación y transformación de los productos locales: ampliación de dos fábricas de quesos (Villarrín de Campos y Tapioles), creación de una fábrica de embutidos (Coreses) y de dos panaderíasbollerias (Torres del Carrizal y Pozoantiguo) o la instalación de una empresa dedicada a la elaboración del pimentón y otras especias (Villalpando). La mayoría de los promotores, en concreto en las primeras, son propietarios privados, mientras que en las segundas corresponden casi siempre a empresas y a una cooperativa. La inversión de capital presenta grandes disparidades debido a la pequeña envergadura económica de muchas de las acciones; casi la mitad de las mismas se halla por debajo del millón de ptas., mientras que las restantes oscilan desde esa cantidad hasta los 50,6 millones de ptas. Las ayudas públicas aportan desde el 38 hasta el $55 \%$ de la inversión, aunque en las acciones de diversificación de la producción agraria la subvención equivale a la mitad de los gastos realizados en la puesta en funcionamiento de dicha actividad productiva.

Finalmente, se debe citar la medida de conservación y mejora del medio ambiente y del entomo. En este caso, el número de actuaciones se sitúa en 28 (FIGURA 4), que se dedican sobre todo al equipamiento de locales culturales de varios núcleos de población; también se centran en la rehabilitación de algunas iglesias de cierto valor histórico-artístico, en el establecimiento de puntos de reciclaje de residuos o en la recuperación-protección de algunos parajes de cierto valor medioambiental (Andavías) y en la realización de varias publicaciones con el fin de divulgar los variados atractivos de la comarca. Los promotores encargados de la puesta en marcha de estas acciones son casi siempre instituciones o entidades

${ }^{13}$ En el mes de julio, ha aparecido una noticia en la prensa escrita según la cual en la localidad vallisoletana de Cuenca de Campos se está ampliando el matadero dedicado al sacrificio de palomas. Es una prueba más de la importancia que está adquiriendo, en la Tierra de Campos, la vieja tradición de la cria de palomas, cuyo simbolo más señero son sus abundantes palomares; éstos, construcciones representativas de la cultura del barro (adobe y tapial), ofrecen una rica y variada tipologia y morfología. 
colectivas, como los ayuntamientos, las asociaciones de tipo cultural, la iglesia o el propio GAL.. En la mayoría de las ocasiones se trata de actuaciones complementarias de las medidas anteriores, de ahi que una parte considerable de las mismas sea financiada integramente con capital público, mientras que en las restantes la aportación se halla entre el 32 y el $70 \%$ de la inversión.

Asi pues, tras el análisis del LEADER de Tierra de Campos se puede concluir que, hasta ahora, sus resultados son bastante favorables, en comparación con los otros programas; prueba de su relativo mayor dinamismo es que se han consolidado o creado unos 22 puestos de trabajo en actividades que nada tienen que ver con el proceso de producción agrario, pero que se localizan en los espacios rurales. Todo ello nos puede servir para poder evaluar la eficiencia y eficacia de las iniciativas emanadas y desarrolladas por la propia población rural, en consonancia con la filosofia de los programas de desarrollo rural. Es más, las tres iniciativas de mayor aceptación (turismo rural, la comercialización y valoración de la producción agraria y las PYMEs) son una prueba bastante fehaciente de que el programa, a pesar de sus limitaciones intrínsecas, está logrando constituir un relativo tejido económico que pueda servir de complemento a su tradicional actividad agraria y permitir que paulatinamente se vaya imponiendo la plurifuncionalidad en estos espacios rurales y al mismo tiempo se diversifican sus fuentes de ingresos.

\section{LOS PROGRAMAS PRODER: SU INTERVENCIÓN EN COMAR- CAS FRONTERIZAS CON FUERTE ATRASO SOCIOECONÓ- MICO.}

Las dos comarcas afectadas por los PrODER, Sanabria y Sayago, mantienen más similitudes entre sí que las comarcas LEADER. Ambas constituyen frontera con Portugal, en donde los territorios conservan las mismas características geográficas, y están aquejadas de unos problemas endógenos y exógenos parecidos: despoblamiento y progresivo envejecimiento de la población, desarticulación del territorio y de las estructuras económicas y su posición alejada de las áreas más dinámicas, entre otros. Todos estos factores se convierten en serios obstáculos para que se dinamicen y para que arraiguen en las mismas los programas de desarrollo rural integrado.

Ambas comarcas se integran en las unidades morfológicas desarrolladas en el Oeste de la provincia: la penillanura granítica al Sur, en Sayago, y un relieve más montañoso al Norte, en Sanabria. Dichas formaciones van a condicionar su desarrollo económico, sobre todo influirán en la actividad agraria, cuyas orientaciones fundamentales son la ganadería y la silvicultura, frente al occidente de la provincia que presenta una aptitud agricola. Al mismo tiempo, dichas actividades tradicionales se pueden convertir en posibles alternativas económicas de cara a los programas de innovación rural. Disponen de abundantes recursos naturales que pueden ser explotados de acuerdo a las nuevas funciones asignadas a los espacios rurales; para lograr mejor esos objetivos se deben combinar dichas actividades con el fin de que dichas comarcas conserven lo mejor posible su articulación territorial y no se vean abocadas a convertirse en espacios marginales y prácticamente abandonados. 
En Sanabria y en Sayago, según el Censo de 1996, viven unas 25.600 personas, que ocupan una extensión de $3.460 \mathrm{Km}^{2}$, de lo que se deduce una densidad media de $7,4 \mathrm{hab} . / \mathrm{Km}^{2}$. Esta baja densidad demográfica está intimamente relacionada con las causas anteriormente expuestas, por lo que si no se adoptan las medidas pertinentes para dinamizarlas se pueden convertir en pocos años en verdaderos desiertos demográficos, de ahí que sea necesaria la implantación y el mantenimiento durante los próximos años de los programas de desarrollo rural.

\subsection{El ProDER de la comarca de Sanabria ${ }^{14}$; el patrimonio y el turismo rurales como iniciativas más arraigadas.}

La comarca de Sanabria, en la que se incluye la propia Sanabria y la Carballeda, ocupa el cuadrante Noroccidental de la provincia, siendo el área más montañosa de la misma. Está formada por 28 municipios que ocupan una extensión de 1.898 $\mathrm{Km}^{2}$ y viven 12.000 personas, de lo que se obtiene una densidad media de 6,3 hab. $/ \mathrm{Km}^{2}$. Se trata de una densidad muy baja reflejo del intenso éxodo rural de décadas precedentes. A ello se añade el acusado envejecimiento de la población, tal como se desprende de la edad de los titulares de las explotaciones agrarias, pues sólo el 2,6 de los mismos tiene menos de 34 años, mientras que los de 55 y más años representan mas de las tres cuartas partes. Asi pues, este es el panorama demográfico en el que se desenvuelve la comarca, que junto a otros factores de diversa índole no van a resultar nada favorables para el desarrollo de las distintas iniciativas de innovación rural.

La inversión prevista, para el periodo 1996-99, asciende a unos 1.038 millones de ptas., de los que el 76\% corresponde a las distintas administraciones (U.E., Central, Regional y Local) y el resto es aportado por el capital privado; dichas proporciones se diferencian considerablemente de las presentadas por las iniciativas comunitarias LEADER. Su distribución por medidas diferente bastante, destacando en particular las que tratan de constituir una cierta malla económica en la comarca, como la revalorización del potencial productivo agrario y forestal, el turismo ${ }^{15}$ y el patrimonio ${ }^{16}$ rurales y el fomento de pequeñas empresas, actividades de artesania y servicios (CUADRO 4).

El cuadro financiero previsto aún no se ha ultimado, por lo que en el tercer trimestre del año 1998 la inversión comprometida se situaba en la cuarta parte de la cantidad presupuestada. Se trata de una pequeña proporción, en comparación con los programas LEADER, no obstante, varias son las razones que explican dicha situación, destacando una en particular: el retraso de su comienzo, debido a que

\footnotetext{
${ }^{14}$ El GAL. que lo gestiona es la Asociación para el Desarrollo Integrado de Sanabria y Carballeda (ADISAC) Su sede está en Puebla de Sanabria.

${ }^{15}$ En la medida de turismo rural se incluye el fomento de las inversiones turisticas en el espacio rural dedicadas tanto al agroturismo como al turismo local.

${ }^{16}$ En esta iniciativa se integran la valoración del patrimonio rural, en aquellos núcleos donde domina la actividad agraria, y del patrimonio local, en los núcleos donde no predomina la actividad agraria.
} 
tardó bastante tiempo en ser firmado por las distintas administraciones españolas,

Cuadro 4: Inversión prevista y comprometida en el PRODER de Sanabria (miles de ptas.).

\begin{tabular}{lrrrrrr}
\hline \multirow{2}{*}{ Medidas } & \multicolumn{2}{c}{ Inversión prevista } & \multicolumn{3}{c}{ Inv. comprometida (1) } & \multirow{2}{*}{$\%$ (2) } \\
\cline { 2 - 6 } & Cantidad & $\%$ & \multicolumn{1}{c}{ Cantidad } & \multicolumn{1}{c}{$\%$} & \\
\hline Patrimonio rural & 208.807 & 20,1 & 107.076 & 40,0 & 51,3 \\
Turismo rural & 223.482 & 21,5 & 69.662 & 27,0 & 31,2 \\
PYMEs & 190.619 & 18,3 & 29.836 & 12,0 & 15,6 \\
Servicio a empresas & 114.181 & 11,0 & 22.899 & 9,0 & 20,0 \\
Potencial agroforestal & 266.523 & 25,7 & 27.374 & 11,0 & 10,3 \\
Mejora ext. agroforestal & 34.392 & 3,4 & 1.897 & 1,0 & 5,5 \\
\hline TOTAL & 1.038 .004 & 100,0 & 258.744 & 100,0 & 24,9 \\
\hline Notas: (1): Inversion comprometida hasta el mes de junio de I998. & & & \\
& (2): \% de la inversión comprometida respecto a la prevista.
\end{tabular}

FUENTE: Dirección General de Estructuras Agrarias y Desarrollo Rural. Consejeria de Agricultura y Ganaderia, Junta de Castilla y León. (Elaboración propia).

El reparto de la inversión comprometida por iniciativas mantiene fuertes contrastes internos (CUADRO 4 y FIGURA 5). Dentro de las mismas, las que han alcanzado mayor grado de desarrollo son, en primer lugar, el fomento del patrimonio y del turismo rurales y, en segundo lugar, la creación de PYMEs y la valoración del potencial productivo agrario y forestal; después se sitúan el servicio a las empreSas, que cubre los gastos de gestión y funcionamiento del PRODER, y mucho más lejos se encuentra la medida de la mejora de la extensión agraria y forestal, que se centra en la organización de cursos para formar profesionalmente en determinadas actividades a la población rural. Similar situación se aprecia si las comparamos con la inversión prevista.

El origen del capital, según las medidas, también ofrece disparidades (FIGURA 5). En la de patrimonio rural las subvenciones públicas de las distintas administraciones aportan casi las dos terceras partes de la inversión (U.E $E^{17}$ el $51,5 \%$ y las nacionales el 16,7\%), haciéndose cargo del resto el capital privado. En la de turismo rural la financiación pública asciende al $43 \%$ (U.E $E^{18}: 33 \%$ y las nacionales: $10 \%$ ); en la del fomento de las PYMEs, en la que es mayor la aportación privada $-62 \%$-, las ayudas públicas se sitúan en el $38 \%$ (U.E. $E^{19}: 27 \%$ y las nacionales: $11 \%$ ) y en la de valoración del potencial productivo agrario y forestal intervienen con el $50 \%\left(\mathrm{UE}^{20}: .39 \%\right.$ y las nacionales: $\left.11 \%\right)$. Restan, finalmente, dos medidas: servicio a las empresas y mejora de la extensión agraria y forestal, que son asumi-

\footnotetext{
${ }_{17}^{17}$ Intervienen el FEDER y el FEOGA.

${ }^{18}$ Participa sólo el FEDER.

19 Interviene únicamente el FEDER

${ }^{20}$ Contribuye sólo el FEOGA.
} 
das integramente por el dinero público (U.E $\mathrm{E}^{21} \approx 70 \%$ y las nacionales: $30 \%$ ).

$\mathrm{La}$ incidencia y la distribución de dichas iniciativas por el espacio comarcal no son similares. Nos centraremos en las que presentan un claro componente territorial y sirven para mejorar y ampliar el tejido económico de los diversos municipios. La medida referida a la valoración del patrimonio rural y local es la que, hasta el momento, mayor grado de desarrollo ha alcanzado. Contiene 24 actuaciones (FIGURA 6), que se centran en diversas actividades, como la adecuación de varias áreas fluviales para usos recreativos, la rehabilitación de varios locales culturales, de edificios de valor arquitectónico (el antiguo teatro de Villardeciervos), de un horno comunal (en Cobreros) o el alumbrado del conjunto histórico de Puebla de Sanabria y el acondicionamiento de un tramo del Camino de Santiago, del ferial del ganado o de un local para ubicar el museo etnográfico. Se reparten por toda la comarca y están promovidas en la mayoría de las ocasiones por los propios Ayuntamientos, el GAL. y algunas asociaciones. La mayor parte de dichas acciones es financiada integramente con fondos públicos y en las restantes la aportación se sitúa en el $70 \%$ y a veces supera este umbral; son iniciativas que tratan de mantener en buen estado de conservación el patrimonio heredado, tanto el vinculado con la secular actividad humana, como el relacionado con los recursos naturales, que se pueden convertir en el señuelo para los posibles visitantes de la comarca y que demandan distintas modalidades de turismo rural.

La iniciativa dedicada a crear la infraestructura para acoger a las personas que demandan el turismo rural se ha manifestado en trece actuaciones (FIGURA 6); la mayoría de ellas se han dedicado a rehabilitar casas para el turismo rural y se localizan preferentemente en las proximidades del Parque Natural del Lago de Sanabria (en Galende y Cobreros) y en el Espacio Natural Protegido de la Sierra de la Culebra (Pedralba de la Pradería y Ferreras de Arriba). Los promotores son casi siempre propietarios particulares, aunque a veces las decisiones corren a cargo de algún empresario y de los propios ayuntamientos (publicación de una guía de rutas del Parque Natural de Sanabria y de rutas del contrabando). Las ayudas públicas cubren entre el 32 y el $48 \%$ de los gastos, soportando la parte restante los promotores privados.

El fomento de las pequeñas empresas, actividades de artesanía y de servicios se ha plasmado en nueve acciones (FIGURA 6). Éstas se han centrado en configurar una relativa infraestructura económica para la comarca, destacando, entre otras, la creación de un taller de artesanía, de una empresa para envasar productos artesanos, de un horno asador artesanal, la ampliación de una confitería o la construcción de una nave industrial para la venta de materiales y máquinas para la construcción. En este caso, la mayor parte de los promotores son empresarios, aunque no faltan iniciativas de propietarios particulares; la cuantía de las inversiones se sitúa entre el millón y medio de ptas. y los 41 millones. Las ayudas públicas son menores, entre el 34 y el $40 \%$, mientras que la mayor parte de la inversión es soportada por el capital privado.

Por último, se debe mencionar la iniciativa dedicada a la valoración del poten-

${ }^{21}$ Participa el FEOGA. 
Figura 5

Programa Operativo de Desarrollo Rural en las comarcas de Sanabria y Carballeda (1997-1998)

\section{Inversión comprometida según medidas y la aportación de capital (en pesetas)}

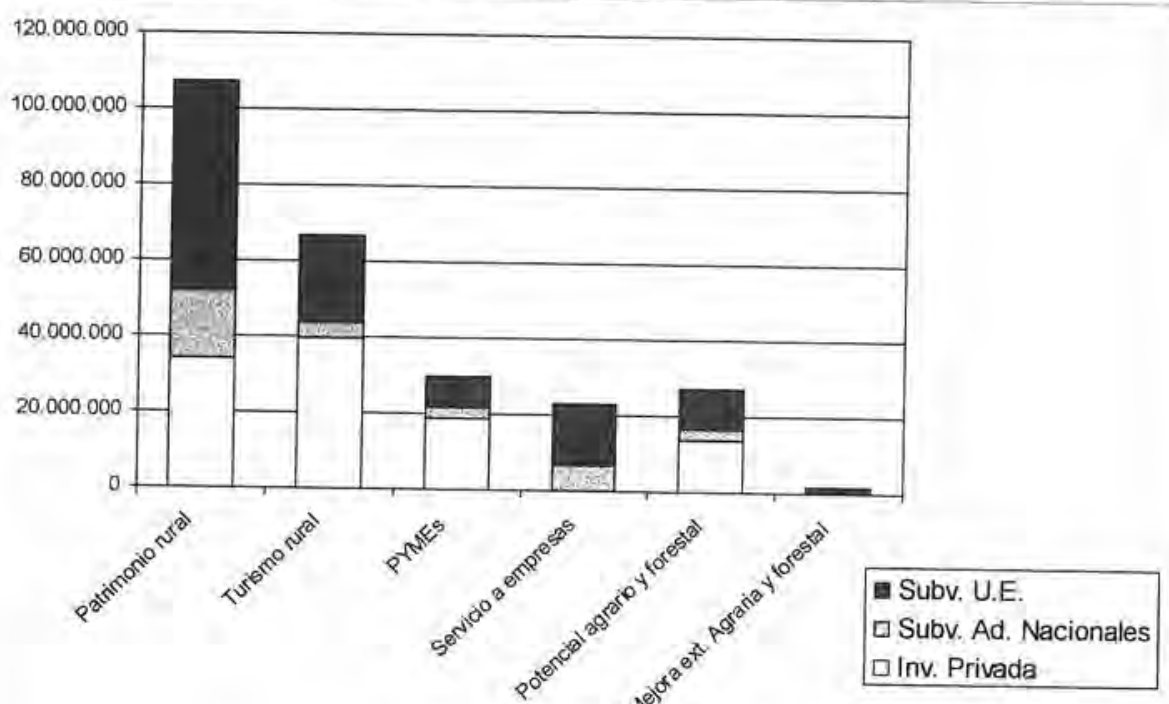

Inversión comprometida según medidas

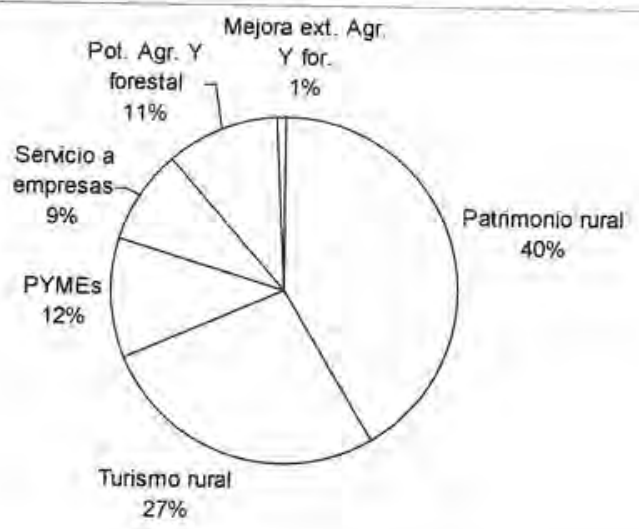


Figura 6: PRODER de la comarca de Sanabria. Número de iniciativas según medidas
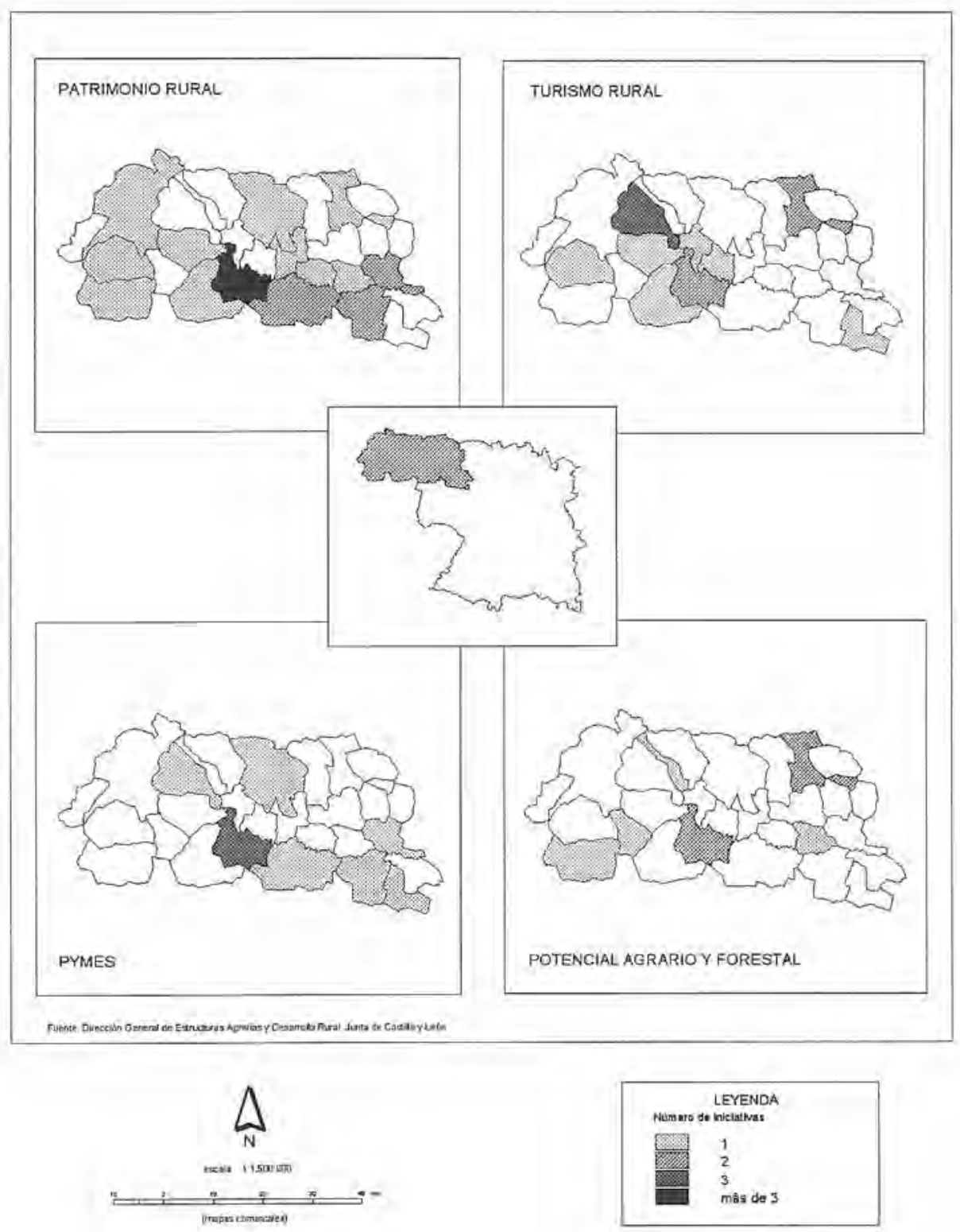
cial productivo agrario y forestal que se ha manifestado en ocho actuaciones (FIGURA 6), Éstas comprenden varias actividades, entre las que se pueden citar las dedicadas a la explotación de los productos locales que ya gozaban de cierta tradición, como el fomento de la came de ternera y buey de Sanabria, la explotación apícola (Muelas de los Caballeros y Hermisende) o la creación de una empresa de servicios forestales, y las centradas en nuevos productos, como la instalación de una granja de zorros cuya producción se transforma alli mismo (Puebla de Sanabria) y la creación de una explotación de conejos silvestres. Las cantidades de dinero invertidas se hallan entre los casi dos millones y los 34 millones de ptas., correspondiendo a las ayudas públicas entre el 35 y el $47 \%$ de los gastos.

De todo ello se deduce que la comarca de Sanabria aún dispone de perspectivas y posibilidades suficientes, en particular el aprovechamiento de sus abundantes recursos naturales, para seguir desarrollando el programa de innovación rural. Estas acciones demostrativas deben servir para involucrar aún más la población local en la elaboración de propuestas económicas que sirvan para fomentar la comarca y evitar su paulatina desarticulación.

\subsection{EI PRODER de la comarca de Sayago ${ }^{22}$ : el fomento de las pequeñas em- presas y el turismo rural como actuaciones más desarrolladas.}

La comarca de Sayago se extiende por el Suroeste de la provincia y comprende todo el ámbito de la penillanura granitica, lo cual va a influir en la propia actividad agraria al desenvolverse sobre suelos de poca miga. Abarca 26 municipios que ocupan una extensión de $1.564 \mathrm{Km}^{2}$ y la habitan 13.649 personas, de lo que resulta una densidad media de $8,7 \mathrm{hab} . / \mathrm{Km}^{2}$; se trata de una densidad similar a todas las comarcas fronterizas. $\mathrm{Al}$ igual que éstas, adolece de las mismas carencias y problemas demográficos, en los que junto al progresivo despoblamiento se ha afianzado un fuerte envejecimiento de la población, tal como se puede comprobar en la edad de los titulares de las explotaciones agrarias, en las que sólo el 8,4 de los mismos tiene menos de 34 años, mientras los de 55 y más años suponen casi las dos terceras partes del censo total.

La inversión prevista, para el periodo 1996-99, se sitúa en los casi 983 millones de pesetas (CUADRO 5). Dicha cantidad es bastante inferior a la de las tres comarcas anteriores. Se distribuye por medidas de forma muy parecida a la de Sanabria; destacan, en primer lugar, las dedicadas a turismo rural y a la valoración del potencial productivo agrario y forestal, $\mathrm{y}$, en segundo lugar, las de renovación del patrimonio rural y el fomento de las pequeñas empresas, de las actividades de artesania y servicios. En el último lugar se hallan las destinadas a ofrecer los servicios a las empresas en el medio rural y la mejora de la extensión agraria y forestal.

\footnotetext{
${ }^{22}$ El titular es la Federación de Asociaciones de Centros de Desarrollo Rural (CEDER) SayagoCoordinadora de Pueblos, que se encarga de su gestión y de coordinar las iniciativas. Su sede se encuentra en Bermillo de Sayago.
} 
Cuadro 5: Inversión prevista y comprometida en el PRODER de Sayago (miles de ptas.).

\begin{tabular}{|c|c|c|c|c|c|}
\hline \multirow{2}{*}{ Medidas } & \multicolumn{2}{|c|}{ Inversión prevista } & \multicolumn{2}{|c|}{ Inv. comprometida (1) } & \multirow{2}{*}{$\%(2)$} \\
\hline & Cantidad & $\%$ & Cantidad & $\%$ & \\
\hline Patrimonio rural & 173.546 & 17,7 & 23.056 & 14,2 & 13,3 \\
\hline Turismo rural & 266.880 & 27,1 & 45.508 & 28,1 & 17,1 \\
\hline PYMES & 180.468 & 18,4 & 56.729 & 35,1 & 31,4 \\
\hline Servicio a empresas & 76.942 & 7,8 & 18.567 & 11,5 & 24,1 \\
\hline Potencial agroforestal & 252.330 & 25,7 & 14.679 & 9,2 & 5,8 \\
\hline Mejora ext. agroforestal & 32.560 & 3,3 & 3.147 & 1,9 & 9,6 \\
\hline TOTAL & 982.726 & 100,0 & 161.686 & 100,0 & 16,5 \\
\hline
\end{tabular}

Notas: (1): Inversión comprometida hasta el mes de junio de 1998.

(2): \% de la inversion comprometida respecto a la prevista.

FUENTE: Dirección General de Estructuras Agrarias y Desarrollo Rural. Consejeria de Agricultura y Ganadería, Junta de Castilla y León. (Elaboración propia).

Al igual que en Sanabria, Ias propuestas del cuadro financiero previsto no han finalizado aún, por lo que la inversión comprometida hasta el tercer trimestre de 1998 es solamente del $16.5 \%$ de la prevista. Se trata del grado de compromiso más bajo de todos los programas de desarrollo nural debido a las razones anteriormente esgrimidas, a las que hay que añadir su mayor retraso en la puesta en funcionamiento y en la elaboración de propuestas (no se realizó ninguna hasta principios del año 1998).

En la distribución de la inversión comprometida por medidas (CUADRO 5 y FIGURA 7) destaca sobre las demás la creación de pequeñas empresas, de las actividades de artesanía y de servicios; le siguen, en orden decreciente, el fomento del turismo y del patrimonio rurales. Y ya a más distancia se hallan la valoración del potencial productivo agrario y forestal, la prestación de servicios a las empresas en el medio rural y la mejora de la extensión agraria y forestal; estas dos últimas, como ya hemos manifestado al comentar la situación de Sanabria, cubren, la primera, la gestión y el funcionamiento del programa y, la segunda, la impartición de cursos de formación profesional con el fin de preparar y adecuar la población rural a determinadas actividades. Parecida situación se deriva de la comparación de las mismas con la inversión prevista en el programa.

$\mathrm{La}$ aportación de capital a las distintas iniciativas presenta diversa procedencia ${ }^{23}$ (FIGURA 7). En la de patrimonio rural, la mayor parte del dinero corresponde a las ayudas públicas de las administraciones (UE.: $49 \%$ y las nacionales: $50,5 \%$ ), pues el capital privado sólo contribuye con el $0,5 \%$; en la del turismo rural la proporción es del $71 \%$ el público ${ }^{24}$ y el $29 \%$ el privado; en la iniciativa del fomento de pequeñas empresas, el capital privado participa de modo mayoritario con el $68 \%$

\footnotetext{
${ }^{23}$ Los fondos estructurales de la U.E. (FEDER y FEOGA) participan en las mismas medidas que en el PRODER de Sanabria.

${ }^{24} \mathrm{La}$ UE. contribuye con el $33 \%$ y las administraciones nacionales con el $38 \%$.
} 
Figura 7

Programa Operativo de Desarrollo Rural en la comarca de Sayago (1997-1998)

Inversión comprometida según medidas y la aportación de capital (en pesetas)

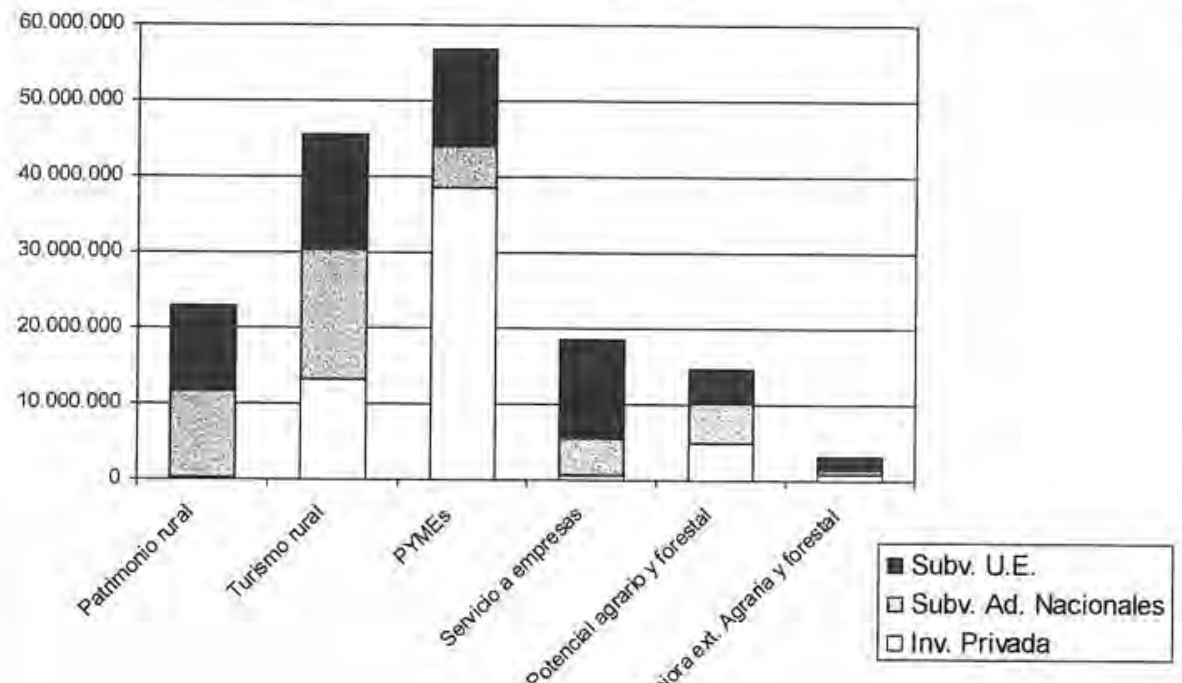

Inversión comprometida según medidas

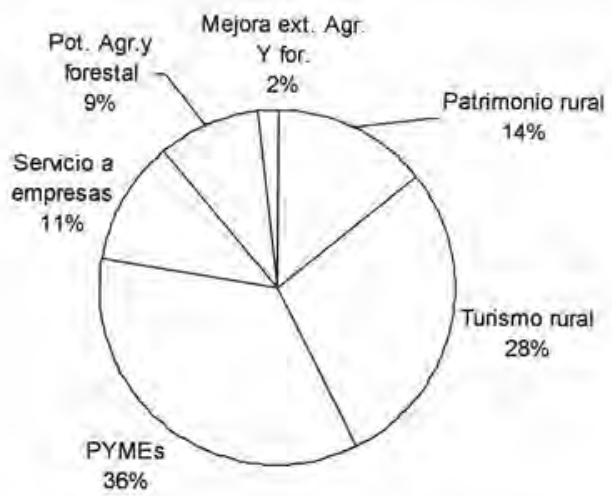


Figura 8: PRODER de la comarca de Sayago.

Número de iniciativas según medidas
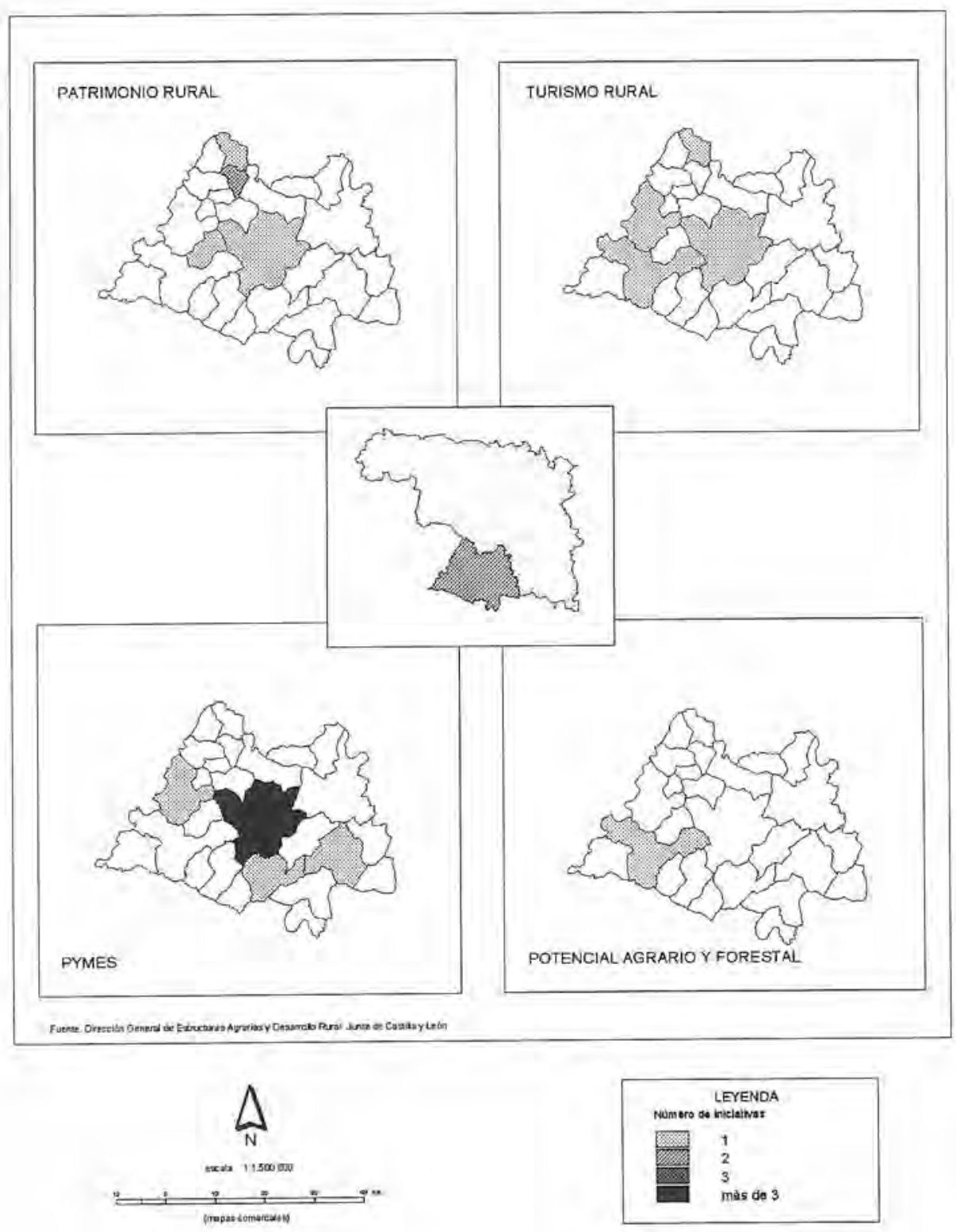
y el resto es subvención pública ${ }^{25}$, y en la valoración del potencial productivo agrario y forestal, el privado contribuye con una tercera parte y el público ${ }^{26}$ asume la proporción restante. Finalmente, restan las dos medidas complementarias que sirven para que funcione el programa o para la impartición de cursos, en las que la mayoría del dinero es de iniciativa pública.

El reparto de las diversas medidas por el espacio de la comarca no es similar; sólo, como ya hemos realizado anteriormente, prestaremos atención a las que sirven para mejorar su malla económica. La centrada en la valoración del patrimonio rural y local comprende nueve actuaciones (FIGURA 8), que se han centrado preferentemente en la adecuación de centros sociales y culturales, en la edición de varias publicaciones y en la mejora de uno de los caminos de acceso a los Arribes de Duero. La inversión oscila desde la 65.000 hasta los 15 millones de ptas. Los promotores son algunos ayuntamientos, el propio G.A.L. y asociaciones, de ahi que la mayor parte del dinero invertido sea de procedencia pública, no obstante, también a veces interviene la financiación privada ${ }^{27}$.

La iniciativa del fomento del turismo rural contiene seis acciones (FIGURA 8), que se dedican básicamente a la construcción de un albergue juvenil (en Fariza) y de un centro de turismo rural (en Bermillo de Sayago), a la readecuación de una casa rural (en Villadepera), a la ampliación de una venta (en Villar del Buey) y a sufragar una publicación sobre rutas e itinerarios geográficos. El capital invertido se sitúa entre los tres y los 47 millones de ptas; los promotores son un propietario particular, dos empresas, un ayuntamiento y el propio G.A.L.; las ayudas públicas asumen desde el 20 hasta $57 \%$ de la inversión total.

La medida dedicada a fomentar las PYMEs, las actividades de artesanía y de servicios se ha manifestado en 9 actuaciones (FIGURA 8). Éstas son muy variadas, localizándose la mayoría en Bermillo de Sayago y destacando en particular las dedicadas a la construcción de una panadería-bolleria artesanales, de un taller de carpintería metálica, de varios bares con tiendas de alimentación o de artesanía incorporadas o de un tanatorio. Las inversiones efectuadas oscilan desde las 300.000 hasta los 23 millones de pesetas, habiendo sido asumidas solamente por propietarios individuales, que han recibido como ayudas públicas entre el $24 \mathrm{y}$ $35 \%$ del capital invertido.

Finalmente, es preciso reseñar la iniciativa que se preocupa de la valoración del potencial productivo agrario y forestal, que sólo incluye una acción y que se refiere a la construcción de una fábrica de elaboración artesanal de queso de oveja, en el municipio de Villar del Buey (FIGURA 8). La inversión asciende a 14,7 millones de ptas., correspondiendo a las subvenciones públicas las dos terceras partes del capital invertido.

Este programa aún se halla en sus inicios, de ahí que sean muchas las perspectivas que tiene por delante. Todavía se pueden abordar propuestas suficientes enca-

${ }^{25}$ La UE. $22 \%$ y las administraciones nacionales: el $10 \%$.

${ }^{26} \mathrm{La} \mathrm{UE}$. el $30 \%$ y las administraciones nacionales, el $36 \%$.

${ }^{27}$ Un buen ejemplo es el acondicionamiento de un centro social por el Ayuntamiento de Muga de Sayago que se ha hecho cargo del $70 \%$ de la inversión. 
minadas al aprovechamiento integral de sus abundantes y variados recursos. Es más, es necesario que sigan en esta misma línea de actuaciones con el fin de lograr alternativas económicas que reduzcan la apatía de la población rural mantenida hasta ahora. Se ha abierto un nuevo campo, con amplias posibilidades, donde caben muchas iniciativas que tomen como base del desarrollo la explotación integral y sostenible de los recursos endógenos. Si queremos que se conserven los espacios rurales, es preciso seguir fomentando los programas de innovación rural como instrumentos dinamizadores de sus estructuras económicas y articuladores de sus territorios.

\section{VALORACIONES FINALES DE LOS PROGRAMAS DE DESA- RROLLO RURAL.}

A pesar de los desiguales resultados de los programas de desarrollo rural en la provincia de Zamora, sobre todo los PRODER, conviene poner de manifiesto que de ellos se derivan aspectos bastante positivos, aunque, por supuesto, no hemos de obviar que también adolecen de insuficiencias y limitaciones. Quizá los exponentes más claros y favorables de esa situación son, entre otros, en primer lugar, la movilización y la inversión del capital privado, animado por las ayudas públicas, en iniciativas que tratan de obtener valor añadido de los recursos naturales, a veces poco aprovechados, y que, al mismo tiempo, permiten obtener beneficios de dichas inversiones. Éstas han de servir para dotar, ampliar y mejorar là mallá económica de las comarcas. En segundo lugar, las propuestas emanan desde abajo (efecto ascendente), es decir, la propia población rural es la que se encarga de proponer ideas ante los grupos de acción local, que actúan de asesores e informadores, y también interviene en la toma final de decisiones, en particular eligiendo sus preferencias y las posibles virtualidades de las inversiones. Y, en tercer lugar, se han creado inquietudes y expectativas en el mundo rural, implicando a los actores sociales locales y tratando de mejorar el tejido básico local; se ha abierto un nuevo campo en el que ocupan un lugar preferente la explotación racional y el aprovechamiento sostenible de los recursos endógenos.

Los programas de innovación rural en Zamora están permitiendo, en general, que se adopten proyectos basados en el aprovechamiento de los recursos locales. No obstante, aún se pueden abordar más iniciativas en las diferentes comarcas que traten de fomentar las potencialidades de que disponen las mismas y sirvan para paliar el atraso socioeconómico en el que se hallan inmersas. En efecto, la comarca de Aliste puede seguir avanzando en las iniciativas que utilicen el paisaje como recurso (turismo rural o la valoración de espacios de singular contenido ecológico), en las que se basen en la valoración de los productos endógenos (la producción de carne de razas autóctonas -vacuno alistano-, la industria agroalimentaria, el aprovechamiento forestal y de productos derivados del bosque, la explotación de los recursos minerales - granito, pizarras o arcillas- o la actividad cinegética en la Sierra de la Culebra) o en la introducción de actividades que se adaptan plenamente a las características geográficas de la comarca.

La comarca de La Tierra de Campos, que es donde el programa ha alcanzado más desarrollo, debe seguir en la línea de fomentar las propuestas que tomen al 
desarrollo rural como la base de su desenvolvimiento económico. Ha de seguir profundizando en propuestas que se apoyen en el turismo rural como recurso (la integración en el mismo de los parajes occidentales y próximos al río Esla, tomando a éste como núcleo de las actividades, la valoración del rico y variado patrimonio rural); el fomento de pequeñas empresas que se dediquen a la transformación de los productos agrarios locales (industrias agroalimentarias); la protección del medio ambiente y del entorno, sobre todo en las inmediaciones de las Lagunas de Villafáfila, de las amplias zonas endorréicas o de las estepas cerealistas, claros ejemplos de la biodiversidad biológica; y continuar con las medidas centradas en la valoración y comercialización de la producción agraria, introduciendo nuevos yacimientos de diversificación de la producción agraria (similares a los ya ensayados: la función actual de los palomares), que sean capaces de aportar ingresos agrarios complementarios a las comunidades rurales.

La comarca de Sanabria ha de continuar en la senda de potenciar sus variados recursos económicos. Debe seguir fomentando el turismo rural como la base sobre la que ha de girar el resto de las actividades; dispone de suficientes recursos naturales, como el lago de Sanabria, la pesca y la caza que han de servir de señuelo y al mismo tiempo convertirse en factores capaces de atraer y crear la suficiente infraestructura para cubrir la posible demanda que se genere. También se han de centrar en la puesta en valor de su potencial agrario y forestal, primando las actuaciones que se dediquen a la transformación de los productos alimentarios, al fomento de productos locales (carne bovina sanabresa, habones, quesos,...) o el impulso de actividades vinculadas con la silvicultura o la apicultura; además, de la puesta en explotación de determinados recursos minerales, como las canteras de granito o de pizarras, que incluso podrían servir para recuperar y potenciar la rica arquitectura popular y, en general, el patrimonio rural.

La comarca de Sayago, aunque le queda bastante camino por recorrer, puede mantener la trayectoria ya iniciada de impulso de aquellas actuaciones que toman como base los recursos locales. El turismo rural se debe seguir potenciando, pues la comarca dispone de los suficientes atractivos para que se convierta en uno de los motores del desarrollo (son muchas las posibilidades turísticas que se derivan de la zona de los Arribes del Duero). Se ha de promocionar, asimismo, Ia formación de pequeñas empresas que se dediquen a la explotación de sus variados recursos (silvícolas -montanera, carboneo, setas, o plantas aromáticas-, apícolas o minerales -granito y caolín). Y también se debe continuar con la búsqueda y el fomento de la valoración del potencial agrario que sirva de alternativa a su tradicional actividad agraria, centrándose en actuaciones dedicadas a un mejor aprovechamiento de los pastizales como sustento de la cabaña ganadera extensiva, bien de aptitud cárnica de calidad (raza autóctona vacuna), bien láctea (ovino) para elaborar quesos de calidad. Además, tampoco debemos obviar otras actuaciones destinadas a actividades cinegéticas o al cuidado de las charcas donde pueden ser criadas tencas o ranas para su comercialización.

En definitiva, nos encontramos ante comarcas con grandes potencialidades económicas en un sentido amplio, pero también adolecen de fuertes estrangulamientos. Esperemos que las iniciativas de innovación rural y las que se perfilen en un futuro inmediato, como continuación de la filosofia de desarrollo rural integrado, 
permitan frenar la decadencia y la desarticulación de las zonas rurales de Zamora. Al menos, los programas ejecutados hasta el momento han servido para valorar determinados recursos, para impulsar ciertas propuestas y para introducir mejoras en la estructura económica de las comarcas donde están interviniendo.

\section{BIBLIOGRAFIA.}

ALARIO, M. Y GÜEMES, T. (1998): «Los programas de desarrollo rural integral en Castilla y León', en VV. AA.: IX Coloquio de Geografia Rural. Comunicaciones. Vitoria, Departamento de Geografia, Prehistoria y Arqueologia, Universidad del País Vasco, pp. 13-21.

COMISIÓN DE LAS COMUNIDADES EUROPEAS (1988): El futuro del mundo rural. COM (88) 501 final: 99 pp. Bruselas, 17 de octubre de 1988.

-- (1997): AGENDA 2000. Por una Unión más fuerte y amplia. COM(97) 2000 final. Boletín de la Unión europea. Suplemento 5/97.

DECLARACIÓN DE CORK (1996): «Por un Medio Rural Vivo. Conferencia Europea sobre Desarrollo Rural. Europa Rural - Perspectivas de Futuro» (Cork, 9 noviembre de 1996), en Agricultura y Sociedad, no 82 (1997), pp. 291-294.

LÓPEZ PASTOR, A.T. (1998): «La transcendencia del desarrollo rural en el nuevo siglo. Los Programas Leader y Proder castellano-leoneses», en $V /$ Congreso de Economía de Castilla y León, Zamora (26-28 de noviembre), 8 pp. (Mimeografiado).

LóPEZ TRIGAL, L. (Dir.)/ MAYA FrADES, A. (Coautor) (1994): Zamora. Un espacio de frontera. Zamora, Ed. Fundación Rei Afonso Henriques.

LÓPEZ TRIGAL, L. (Dir.)/ MAYA FrADES, A. (Coautor) (1998): La población en el desarrollo de Castilla y León. Valladolid, Consejo Económico y Social de Castilla y León.

MAYA Frades, A. (1997): «El sector primario en las comarcas fronterizas de Zamora), en LÓPEZ TRIGAL et Al. (Coord.) La articulación territorial de la raya hispano-portuguesa. Actas Simposium Vilar Formoso, 1996. Zamora, Ed. Fundación Rei Afonso Henriques, pp. 95-109.

PÉREZ ESPARCIA, J. y NOGUERA TUR, J. (1998): «La eficacia de las políticas de desarrollo ruraly, en VV. AA. .. LX Coloquio de Geografia Rural. Comunicaciones. Vitoria, Departamento de Geografia, Prehistoria y Arqueologia, Universidad del Pais Vasco, pp. 77-84.

VV. AA. (1999): «Dossier sobre Desarrollo Rural», en Tierras de Castilla y León. Mes de enero, 46 pp.

-- (1998): Desarrollo agrario y desarrollo rural: Los agricultores, nuevos actores de desarrollo. Actas del Congreso Internacional sobre desarrollo rural. Ministerio de Agricultura, Pesca y Alimentación, Madrid.

RESUMEN: Análisis de la incidencia de los programas de desarrollo rural integrado en la provincia de Zamora. Sobre la misma actúan dos iniciativas comunitarias Leaders, en las comarcas de Aliste y en la de Tierra de Campos, y dos Programas de Desarrollo y Diversificación Económica en las Zonas Rurales (PRODER), en las comarcas de Sanabria 
y Sayago. Dichos programas han servido para poner en valor determinados recursos y para ampliar el tejido económico de las mismas.

PALABRAS CLAVE: Desarrollo rural integrado, LEADER, PRODER, turismo rural y valoración agraria y forestal.

SUMMARY: The effect of integrated rural development programmes on the province of Zamora is analysed. In this area two community initiatives Leaders act in the regions of Aliste and Tierra de Campos (It is called Land of Fields due to its landscape characteristics), and two Programmes of Development and Economic Diversification of Rural Areas (PRODER) work in the regions of Sanabria and Sayago. These programmes have come in for underlining certain resources and increasing their financial prospects.

KEY WORDS: Integrated Rural Development, LEADER, PRODER, Rural Tourism and Agricultural and Forest Assessment.

RÉSUMÉ: Analyse de l'incidence des programmes de développement rural intégré dans la province de Zamora. Deux initiatives communautaires LEADER agissent sur cette même province: dans les régions d'Aliste et dans celle de Tierra de Campos, ainsi que deux programmes de Développement et de Diversification Economique dans les Zones Rurales (PRODER), dans les régions de Sanabria et de Sayago. Ces programmes ont servi à mettre en valeur des ressources précises et à augmenter les liens économiques de ces régions.

MOTS CLES: Développement rural intégré, LEADER, PRODER; tourisme rural et évaluation agraire et forestière. 